\title{
HUBUNGAN PARITAS DENGAN HIPEREMESIS GRAVIDARUM DI RUANG BERSALIN RSUD PROVINSI NTB
}

\author{
Ana Pujianti Harahap ${ }^{1}$, Linda Meliati², Tutik Srihandayani ${ }^{3}$ \\ ${ }^{1}$ Prodi DIII Kebidanan, Universitas Muhammadiyah Mataram, email ana.harahap87@gmail.com \\ ${ }^{2}$ Prodi DIII Kebidanan, Universitas Muhammadiyah Mataram \\ ${ }^{3}$ Mahasiswa Prodi DIII Kebidanan, Universitas Muhammadiyah Mataram
}

\section{INFO ARTIKEL}

\section{Riwayat Artikel:}

Diterima: 04-01-2018

Disetujui: 30-01-2018

\section{Kata Kunci:}

Paritas,

Hiperemesis Gravidarum

\begin{abstract}
ABSTRAK
Abstrak: Hiperemesis gravidarum di definisikan sebagai mual muntah yang berlebihan atau tidak terkendali selama masa hamil, yang menyebabkan dehidrasi, ketidak seimbangan elektrolit, atau defisiensi nutrisi, dan kehilangan berat badan. Berdasarkan catatan Register di RSUP NTB Tahun 2012-2013, pada tahun 2012 angka kejadian Hiperemesis Gravidarum sebanyak 25 kasus, tahun 2013 meningkat menjadi 26 kasus, baik yang disertai dengan berbagai penyakit dan tanpa penyakit. Metode penelitian ini bersifat Survey analitik dengan desain cross secsional. Populasi dalam penelitian ini adalah semua ibu hamil trimester I yang tercatat di Register Ruang poli hamil sejumlah 120 orang. Besar sampel dalam penelitian ini sejumlah 120 orang. Sampel yang digunakan pada penelitian ini menggunakan Non Probability sampling dengan total sampel jenuh yaitu pengambilan sampel dari keseluruhan populasi. Hasil penelitian : Karakteristik: sebagian besar sampel berada pada kelompok umur 20-35 tahun sebanyak 69 ibu (57,5\%), paritas sebagian besar pada paritas primipara sebesar 56 ibu (46,7\%). Angka kejadian Hiperemesis Gravidarum di RSUP NTB Tahun 2012-2013 sebanyak 51 ibu (42,5\%). kejadian hiperemesis gravidarum dengan nilai $p=0,003$ artinya Ada hubungan paritas ibu hamil trimester I dengan kejadian hiperemesis gravidarum.Adapun saran yang dapat saya sampaikan di sini yaitu hasil penelitian ini dapat di jadikan bahan penyuluhan, meningkatkan pengetahuan masyrakat tentang hiperemesis gravidarum
\end{abstract}

\begin{abstract}
Hyperemesis gravidarum is defined as excessive or uncontrolled nausea during pregnancy, leading to dehydration, electrolyte imbalances, or nutritional deficiencies, and weight loss. Based on the Register records at the 2012-2013 NTB General Hospital, in 2012 the incidence of Hyperemesis Gravidarum in 25 cases, in 2013 increased to 26 cases, both accompanied by various diseases and without disease. This research method is analytic survey with cross-secsional design. The population in this study were all pregnant women of the 1st trimester recorded in the Register of Polybasics room of 120 people. The sample size in this study is 120 people. The sample used in this study using Non Probability sampling with total sample saturation that is sampling from entire population. Results: Characteristics. most of the samples were in the age group of 20-35 years as many as 69 mothers (57.5\%), parity mostly in primiparity parity of 56 mothers (46.7\%). The incidence of Hyperemesis Gravidarum at NTB Hospital Year 2012-2013 is 51 mothers (42,5\%). the incidence of hyperemesis gravidarum with $p$ value $=0.003$ means There is a parity relationship of trimester pregnant women with the incidence of hyperemesis gravidarum.Adapun suggestions that I can convey here that the results of this study can be made extension materials, increase public knowledge about hyperemesis gravidarum
\end{abstract}




\section{A. LATAR BELAKANG}

Menurut Winkjosastro (2002), salah satu komplikasi atau ketidaknyamanan pada ibu hamil adalah hiperemesis gravidarum terjadi pada 50-90\% wanita hamil adalah mual (nausea) dan muntah (emesis gravidarum).Mual dan muntah merupakan gangguan yang paling sering kita jumpai pada kehamilan muda dan dikemukakan oleh $50-70 \%$ wanita hamil dalam 16 minggu pertama. Kurang lebih 66\% wanita hamil trimester pertama mengalami mual - mual dan 44\% mengalami muntah-muntah.

Hiperemesis Gravidarum lebih banyak terjadi pada wanita yang baru pertama kali hamil atau pada primigravida khususnya dan pada wanita dengan paritas tinggi seperti ibu yang sudah mengalami kehamilan yang ke empat, hal ini tidak terlepas oleh karena faktor psikologis yakni takut terhadap tanggung jawab sebagai ibu bila ibu tersebut tidak sanggup lagi mengurus anak anaknya, ini dapat menyebabkan konflik mental yang dapat memper-berat mual dan muntah (Varney, 2004). Berdasarkan hasil sebuah penelitian dapat disimpulkan bahwa kejadian hiperemesis gravidarum lebih sering dialami oleh primigravida dari pada multigravida, hal ini berhubungan dengan tingkat kestresan dan usia si ibu saat mengalami kehamilan pertama (Nining, 2009).

Bentuk perhatian pemerintah terhadap hiperemesis gravidarum adalah dengan mengadakan penyuluhan kesehatan di pusat pelayanan kesehatan masyarakat (Puskesmas) dan di rumah sakit serta di balai-balai pelayanan kesehatan agar masyarakat umum mengetahui masalah emesis gravidarum dan cara mengatasinya (Anonim, 2012).

Perubahan kondisi fisik dan emosional yang kompleks, memerlukan adaptasi terhadap penyesuaian pola hidup dengan proses kehamilan yang terjadi, konflik antara keinginan, kebanggaan, yang tumbuh dari norma-norma sosio-kultural dan persoalan dalam keadaan kehamilan itu sendiri, dapat merupakan pencetus berbagai gangguan jiwa mulai yang ringan sampai dengan yang berat (Rahmawati, 2011).

Berdasarkan data Dinkes Provinsi NTB, cakupan ibu hamil yang mengalami hiperemesis gravidarum pada trimester I naik dari tahun ke tahun, pada tahun 2010 sebesar 49,7 \% dari jumlah ibu hamil yang berjumlah 139.230 ibu hamil, 2011 naik menjadi 52,4 \% dari jumlah 141.395 ibu hamil dan tahun 2012 naik menjadi 53,24 \% dari 142.240 ibu hamil (Dinkes NTB, 2013).

Studi pendahuluan yang dilakukan di Ruang Poli Hamil RSUP NTB yaitu bulan Januari sampai Desember Tahun 2012 terdapat 65 ibu hamil, dimana yang mengalami hiperemesis gravidarum sebanyak $25(38,46 \%)$ orang. Data ini mengalami peningkatan pada tahun 2013 dimana dari $55 \mathrm{ibu}$ hamil, yang mengalami hiperemesis gravidarum sebanyak 26 orang (47,27\%). (Buku Register Rawat Inap RSUP NTB, 2012-2013)

Berdasarkan penelitian yang dilakukan oleh (Nurul Fadila,2011) tercatat dari tanggal 1 Januari sampai dengan 31 Desember tahun 2011, terdapat 1430 orang ibu hamil di Puskesmas Tanjung Karang dan 30 orang $(2,1 \%)$ ibu hamil diantaranya mengalami hiperemesis gravidarum dari berbagai kalangan paritas dan Tingkat Pendidikan (Buku Register Rawat Inap Puskesmas Tanjung Karang, 2011)

Berdasarkan latar belakang dan fenomena tersebut di atas, peneliti sangat tertarik untuk meneliti tentang "Hubungan Paritas Ibu Hamil Trimester I Dengan Kejadian Hiperemesis Gravidarum Di RSUP NTB, Tahun 2012-2013”

\section{B. METODE PENELITIAN}

Metode yang di gunakan dalam penelitian ini adalah metode penelitian survei analitik dengan desain penelitian cross secsional. Populasi dalam penelitian ini adalah semua ibu hamil trimester I di RSUP NTB Tahun 2012 (Januari-Desember 2012) dan Tahun 2013 (Januari-Desember 2013) adalah 120 orang. Sampel pada penelitian ini adalah seluruh Ibu hamil trimester I di RSUP NTB tahun 2012-2013 dan besar sampel sejumlah 120 orang. Teknik sampling dalam penelitian ini menggunakan Non Probability Sampling dengan Total Sampling/Sampel Jenuh yaitu pengambilan sampel dari keseluruhan populasi.

\section{HASIL DAN PEMBAHASAN}

\section{Karakteristik Sampel}

Karakteristik sampel berdasarkan umur ibu hamil dan paritas ibu hamil.

a. Umur sampel

TABEL 1

Distribusi Sampel Berdasarkan Umur Ibu Hamil

\begin{tabular}{cccc}
\hline No. & Umur & $\begin{array}{c}\text { Jumlah } \\
(\mathrm{n})\end{array}$ & $\begin{array}{c}\text { Persentasi } \\
(\%)\end{array}$ \\
\hline 1. & $<$ 20 tahun & 23 & 19,2 \\
2. & $20-35$ tahun & 69 & 57,5 \\
3. & $>$ 35 tahun & 28 & 23,3 \\
\hline & Total & 120 & 100 \\
\hline
\end{tabular}

Berdasarkan Tabel 1 tersebut diatas dapat dijelaskan bahwa jumlah sampel terbanyak berumur 20-35 tahun yaitu sebanyak 69 orang 
(57,5\%) dan sampel paling sedikit berumur $<20$ tahun yaitu sebanyak 23 orang (19,2\%).

b. Paritas Sampel

\section{TABEL 2}

Distribusi Sampel Berdasarkan Paritas Ibu Hamil

\begin{tabular}{clcc}
\hline No & Paritas & $\begin{array}{c}\text { Jumlah } \\
(\mathrm{n})\end{array}$ & $\begin{array}{c}\text { Persentasi } \\
(\%)\end{array}$ \\
\hline 1. & Primipara & 56 & 46,7 \\
2. & Multipara & 37 & 30,8 \\
3. & Grandemultipara & 27 & 22,5 \\
\hline & Total & 120 & 100
\end{tabular}

Berdasarkan Tabel 2 tersebut diatas dapat dijelaskan bahwa jumlah sampel terbanyak memiliki paritas primipara yaitu sebanyak 56 orang $(46,7 \%)$ dan sampel paling sedikit memiliki paritas grandemultipara yaitu sebanyak 27 orang 22,5\%).

\section{Kejadian Hiperemesis Gravidarum}

\section{TABEL 3}

Distribusi Sampel Berdasarkan Kejadian Hiperemesis Gravidarum Ibu Hamil Trimester

\begin{tabular}{clcc}
\multicolumn{4}{c}{ I Di RSUP NTB Tahun 2012-2013 } \\
\hline No & Hiperemesis & $\begin{array}{c}\text { Jumlah } \\
\text { (n) }\end{array}$ & $\begin{array}{c}\text { Persentasi } \\
(\%)\end{array}$ \\
\hline Gravidarum & Ya & 51 & 42,5 \\
2. & Tidak & 69 & 57,5 \\
\hline & Total & 120 & 100 \\
\hline
\end{tabular}

Berdasarkan Tabel 3 tersebut diatas dapat dijelaskan bahwa sampel lebih banyak tidak mengalami Hiperemesis Gravidarum yaitu sebanyak 69 orang $(57,5 \%)$ dibandingkan dengan responden yang mengalami Hiperemesis Gravidarum yaitu sebanyak 51 orang $(42,5 \%)$.

\section{Hubungan paritas ibu hamil trimester I dengan kejadian hiperemesis gravidarum}

TABEL 4

Hubungan Paritas Ibu Hamil Trimester I Dengan Kejadian Hiperemesis Gravidarum Di RSUP NTB Tahun 2012-2013

\begin{tabular}{|c|c|c|c|c|c|c|c|c|}
\hline \multirow{3}{*}{$\begin{array}{l}\text { No } \\
\cdot\end{array}$} & \multirow{3}{*}{ Paritas } & \multicolumn{4}{|c|}{$\begin{array}{l}\text { Hiperemesis } \\
\text { Gravidarum }\end{array}$} & \multirow{2}{*}{\multicolumn{2}{|c|}{ Jumlah }} & \multirow{3}{*}{$\begin{array}{l}P \\
\text { valu } \\
\boldsymbol{e}\end{array}$} \\
\hline & & \multicolumn{2}{|c|}{$\mathrm{Ya}$} & \multicolumn{2}{|c|}{ Tidak } & & & \\
\hline & & $\mathrm{n}$ & $\%$ & $\mathrm{n}$ & $\%$ & $\mathrm{n}$ & $\%$ & \\
\hline 1. & Primipara & 3 & 57,1 & 2 & 42, & 56 & 10 & \\
\hline 2. & Multipara & 2 & 21,6 & 4 & 9 & 37 & $\mathrm{O}$ & 0,003 \\
\hline \multirow[t]{4}{*}{3.} & Grandemultipar & 8 & 40 & 2 & 78 & 27 & 10 & \\
\hline & $\mathrm{a}$ & 11 & 7 & 9 & 4 & & o & \\
\hline & & & & 16 & 59 & & 10 & \\
\hline & & & & & 3 & & 0 & \\
\hline \multirow[t]{2}{*}{ Total } & & 51 & 42, & 6 & 57,5 & 12 & 10 & \\
\hline & & & 5 & 9 & & $\mathrm{O}$ & $\mathrm{O}$ & \\
\hline
\end{tabular}

Dari Tabel 4 terlihat bahwa sampel yang mengalami Hiperemesis Gravidarum sejumlah 51 orang $(42,5 \%)$ dan yang tidak mengalami Hiperemesis Gravidarum sejumlah 69 orang (57,5\%). Paritas primipara lebih cendrung mengalami Hiperemesis Gravidarum, Paritas multipara yang cendrung tidak mengalami Hiperemesis Gravidarum.

Dari hasil uji statistik menggunakan uji chi square dengan SPSS versi 16 pada tingkat kesalahan $5 \% \quad(\alpha=0,05)$ diperoleh nilai probabilitas/signifikansi $(\mathrm{p})=0,003$ sehingga dapat ditarik kesimpulan bahwa p < a ( $p=0,003<0,05$ ) yang artinya Ada Hubungan antara paritas ibu hamil trimester I dengan kejadian Hiperemesis Gravidarum di RSUP NTB Tahun 2012-2013.

\section{TEMUAN ATAU DISKUSI}

\section{Umur Ibu Hamil}

Berdasarkan Tabel 41 menunjukkan umur terbanyak yaitu pada rentang umur 20-35 tahun berjumlah 69 orang $(57,5 \%)$, karena usia tersebut merupakan usia aman untuk kehamilan.Pada usia produktif (20-35 tahun) terjadi kesiapan respon maksimal baik dalam hal mempelajari sesuatu atau dalam menyesuaikan hal-hal tertentu dan setelah itu sedikit demi sedikit menurun seiring dengan bertambahnya umur. Selain itu pada usia produktif, mereka lebih terbuka terhadap orang lain dan biasanya mereka akan saling bertukar pengalaman tentang hal yang sama yang pernah mereka alami (Hurlock, EB, 2002).

Penelitian ini di dukung oleh penelitian yang dilakukan di Bangsal Kebidanan RSUD Curup Kabupaten Rejang Lebong Tahun 2006dari 401 Sampel, ibu hamil yang berumur $<20$ tahun sebanyak $15(3,74 \%)$ orang, sedangkan ibu hamil yang berumur 20-35 tahun sebanyak $326(81,30 \%)$ orang, dan ibu hamil yang berumur $>35$ tahun sebanyak 60 (14,96\%) orang (Elvanam, 2006).

2. Paritas ibu hamil

Berdasarkan Tabel 2 dapat dijelaskan bahwa jumlah sampel terbanyak memiliki paritas primipara yaitu sebanyak 56 orang $(46,7 \%)$.

Ibu dengan paritas primipara adalah kelompok dengan keadaan yang cenderung lebih rentan untuk terkena komplikasikomplikasi pada kehamilannya, dikarenakan kondisi psikologis yang terjadi pada ibu yang baru pertama hamil. Dimana pada saat kehamilannya yang pertama, ibu merasa belum siap untuk menerima kehamilannya dan cenderung manja apabila terjadi hal yang tidak biasa terhadap dirinya dan kehamilannya 
(Hayati, 2004). Penelitian ini di dukung oleh penelitian yang dilakukan di Puskesmas Tanjung Karang Tahun 2011 bahwa dari 60 sampel ibu hamil yang diamati, ibu hamil yang kelompok

\section{E. SIMPULAN DAN SARAN}

Dari penelitian yang yang telah di lakukan pada hubungan paritas ibu hamil trimester I di RSUP NTB bulan Februari tahun 2014 dapat disimpulkan sebagai berikut :

1. Umur ibu hamil Trimester I yang mengalami Hiperemesis Gravidarum di RSUP NTB Tahun 2012-2013 terbanyak berumur 20-35 tahun sebanyak 69 orang (57,5\%).

2. Paritas ibu hamil Trimester I yang mengalami Hiperemesis Gravidarum di RSUP NTB Tahun 2012-2013 terbanyak paritas primipara sebanyak 56 orang (46,7\%).

3. Kejadian Hiperemesis Gravidarum di RSUP NTB Tahun 2012-2013 sebanyak 51 orang (42,5\%).

4. Ada hubungan antara paritas ibu hamil trimester I dengan kejadian Hiperemesis Gravidarum di RSUP NTB Tahun 20122013 ( $\mathrm{P}$ Value $=0,003)$

Kemudian tim peneliti memberikan beberapa saran sebagai berikut:

1. Bagi pihak RSUP NTB

Bagi petugas kesehatan diharapkan dapat memberikan penyuluhan-peneyuluhan mengenai apa gejala dan tanda hiperemesis gravidarum dengan demikian diharapkan kualitas pelayanan kesehatan dapat ditingkatkan sehingga angka kejadian yang berhubungan dengan penyakit yang ditimbulkan dari hiperemesis gravidarum dapat ditangani dengan cepat dan baik.

2. Bagi Masyarakat

Diharapkan masyarakat dapat meningkatkan kunjungan Antenatal untuk mengurangi angka kejadian hiperemesis gravidarum dengan cara rutin memeriksakan kehamilannya di pelayanan kesehatan terdekat.

3. Bagi Institusi Pendidikan

Diharapkan kepada institusi pendidikan agar dapat menambah bahan kepustakaan yang berhubungan dengan penelitian yang sudah dilakukan.

\section{DAFTAR PUSTAKA}

Depkes RI. 2004. Asuhan Persalinan Normal. Jakarta: Jaringan Nasional Pelatihan Klinik Kesehatan Reproduksi.

Helen Varney. 2007 .Buku Ajar Kebidanan .EGC : Jakarta.

Kurniawati D. dan Mirzanie H, 2009, Obgynacea, Yogyakarta : Tosca Entreprise.

Manuaba, Ida Bagus Gede. 2009. Memahami Kesehatan Reproduksi Wanita. EGC: Jakarta.

Manuaba, Ida Bagus Gede. 2007. Pengantar Kuliah Obstetri. EGC: Jakarta.

Manuaba I.B.G, 2008, Ilmu Kebidanan, Penyakit Kandungan \& Keluarga Berencana untuk Pendidikan Bidan, EGC, Jakarta.

Notoatmodjo S. 2005. Metodologi Penelitian Kesehatan.Rineka Cipta: Jakarta.

Notoatmodjo, 2002, Metodologi Penelitian Kesehatan, Bineka Cipta, Jakarta.

Ovedoff, 2002, Kapita Selekta Kedokteran, Binarupa Aksara, Jakarta. 